\title{
Active Supplementation With Magnesium Sulfate May Be Associated With Worse Prognosis in Sepsis: A Retrospective Analysis of The MIMIC-IV Database
}

\section{Lulan Li}

Southern Medical University Nanfang Hospital

Shiyu Zhou

Southern Medical University School of Public Health

Qiaobing Huang

Southern Medical University School of Basic Medical Sciences

Hongbin $\mathrm{Hu}$

Southern Medical University Nanfang Hospital

Jie Wu

Southern Medical University Nanfang Hospital

\section{Zhongqing Chen}

Southern Medical University Nanfang Hospital

\section{Shengli An}

Southern Medical University School of Public Health

\section{Zhenhua Zeng ( $\nabla$ zhenhuazeng.2008@163.com )}

Southern Medical University Nanfang Hospital https://orcid.org/0000-0002-9509-1536

\section{Research}

Keywords: sepsis, hypomagnesemia, hypermagnesemia

Posted Date: March 24th, 2021

DOI: https://doi.org/10.21203/rs.3.rs-331143/v1

License: (c) (i) This work is licensed under a Creative Commons Attribution 4.0 International License. Read Full License 


\section{Abstract}

Background: Magnesium plays pivotal roles in physiological processes. Previous studies have shown that magnesium acts as an important mediator in ameliorating cellular injury and preventing the release of proinflammatory cytokines in septic patients. Therefore, we speculated that the serum magnesium ion level may affect the outcome of sepsis. However, research in this area is rarely reported and it is worth exploring.

Methods: We conducted a retrospective study based on the MIMIC-IV database. According to the timeweighted magnesium levels during the ICU stay, we analyzed the relationship between serum magnesium levels and 28-day mortality and 90-day mortality using a time-dependent Cox proportional hazard model and restricted cubic splines. Additionally, we examined the effect of magnesium sulfate supplementation on prognosis with a time-fixed and time-dependent Cox model and restricted cubic splines.

Results: In total, 8175 patients were included in this study. Patients with hypo-, normo- and hypermagnesemia were $22.87 \%, 66.84 \%$, and $10.29 \%$, respectively. When adjusted for confounders, hypermagnesemia was significantly associated with both 28-day mortality $(\mathrm{HR}=1.42,95 \% \mathrm{Cl}=1.23-1.64$, $p<0.001)$ and 90 -day mortality $(\mathrm{HR}=1.42,95 \% \mathrm{Cl}=1.24-1.64, p<0.001)$. However, no significant difference was found between hypomagnesemia and mortality of septic patients (28-day mortality: HR=1.09, 95\% $\mathrm{Cl}=0.86-1.37, p=0.486,90$-day mortality: $\mathrm{HR}=1.06,95 \%=0.85-1.34, p=0.573)$. For those who received magnesium sulfate supplementation, there was no significant difference among hypo-, normo-, and hypermagnesemia before $\mathrm{MgSO}_{4}$ supplementation. Interestingly, subsequent hypermagnesemia (28-day mortality: $\mathrm{HR}=1.44,95 \% \mathrm{Cl}=1.17-1.78, p=0.001,90$-day mortality: $\mathrm{HR}=1.43,95 \% \mathrm{Cl}=1.16-1.77, p=0.001)$, and even still hypomagnesemia (28-day mortality: $\mathrm{HR}=1.51,95 \% \mathrm{Cl}=1.15-1.99, p=0.003,90$-day mortality: $\mathrm{HR}=1.53,95 \% \mathrm{Cl}=1.18-1.99, p=0.001)$ after $\mathrm{MgSO}_{4}$ supplement were significantly associated with increased 28-day and 90-day mortality after adjustment for confounders.

Conclusion: Hypermagnesemia was significantly associated with higher risk of 28-day mortality and 90day mortality. Active supplementation with magnesium sulfate may be associated with a worse prognosis in sepsis.

\section{Introduction}

Magnesium (Mg), as the fourth most abundant electrolyte in the body, plays pivotal roles in physiological processes[1-4]. Mg may exert immunological, respiratory, and cardiovascular effects through energy storage and transfer, protein and enzyme synthesis, inflammation and homeostasis[1-3]. Typically, the normal range of $\mathrm{Mg}$ is 1.7-2.4 $\mathrm{mg} / \mathrm{dl}(0.66-1.05 \mathrm{mmol} / \mathrm{L})$, hypomagnesemia was defined as serum $\mathrm{Mg}$ level less than $1.7 \mathrm{mg} / \mathrm{dl}$, and hypermagnesemia was described as a serum $\mathrm{Mg}$ level higher than 2.4 $\mathrm{mg} / \mathrm{dl}[5]$. Mg is absorbed in the small intestine and excreted primarily in the kidneys[5]. Mg disorders, including hypomagnesemia and hypermagnesemia, are common electrolyte abnormalities in critically ill patients due to their high severity of illness and the complex therapies provided[6, 7]. A recent 
retrospective cohort study revealed that the prevalence of hypomagnesemia was $23.8 \%$ and that the incidence of hypermagnesemia was $11.9 \%$ among adult patients admitted to the intensive care unit[7]. Reports have shown that hypomagnesemia and hypermagnesemia could lead to important clinical symptoms and consequences, such as cardiac arrhythmias and neurotoxicity[8]. Several studies have shown that serum Mg levels are an independent risk factor for death and hypomagnesemia or hypermagnesemia have been associated with increased mortality rates in critically ill patients[9-12]. This understanding is particularly important in patients who develop sepsis, triggered by a dysregulated host response to infection with high mortality $[13,14]$. These patients are more likely to have $\mathrm{Mg}$ abnormalities[11, 15]. There are various reasons why septic patients may acquire abnormal serum $\mathrm{Mg}$ levels, such as inadequate intake of $\mathrm{Mg}$, oversupplementation with magnesium sulfate (MgSO4), drugs, such as proton pump inhibitors and diuretics, or kidney dysfunction[6]. Interestingly, some studies have demonstrated that $\mathrm{Mg}$ is an important mediator that ameliorates cellular injury and prevents the release of proinflammatory cytokines during the development of sepsis $[3,16]$. However, the impact of abnormal $\mathrm{Mg}$ levels on patients with sepsis is rarely reported and the specific association between serum $\mathrm{Mg}$ and mortality of septic patients is still not clear. In addition, to the best of our knowledge, the influence of magnesium sulfate supplementation on the risk of mortality in septic patients has not been studied before. Therefore, we conducted a retrospective clinical trial using the MIMIC-IV database in light of both time-fixed and time-varying models to explore the impact of serum $\mathrm{Mg}$ concentration on clinical outcomes (mainly 28-day and 90-day mortality), and further evaluate the potential association between magnesium sulfate supplementation and the mortality rate of septic patients.

\section{Materials And Methods}

\section{Data extraction}

This retrospective study extracted data from the Multiparameter Intelligent Monitoring in Intensive Care Database IV (MIMIC IV), which contains ICU patient data ranging from 2008 to 2019. This database was approved by the Institutional Review Boards (IRB) of the Massachusetts Institute of Technology (MIT) and Beth Israel Deaconess Medical Center (BDMC). One of the authors (Shiyu Zhou) obtained access to reach and extract the data (certification No. 35931520)

\section{Inclusion and Exclusion criteria}

Adult patients diagnosed with sepsis within 24 hours after ICU admission were eligible for inclusion into the study. The exclusion criteria were patients without any hospitalization records, patients who lacked Mg measurement during the whole ICU stay, and patients less than 16 years old.

\section{Sepsis definition}

Sepsis was defined as life-threatening organ dysfunction caused by a dysregulated host response to infection (sepsis 3.0). Infectious patients with a SOFA score of 2 points or more were diagnosed with sepsis[14]. 


\section{Endpoints}

The primary endpoints of the study were 28-day mortality and 90-day mortality rates, and the secondary endpoint was whether supplementation with magnesium sulfate was beneficial or harmful.

\section{Statistical analysis}

Continuous variables are reported as medians (interquartile ranges [IQRs]) and were compared using ANOVA, while categorical variables are presented as counts with percentages and were compared with the chi-square test.

The risks of 28- and 90-day mortality were estimated by time-dependent Cox proportional hazard model based on continuous and categorical Mg levels. In our primary analysis, Mg levels were treated as the time-varying variable and divided into three levels (hypomagnesemia $<1.7 \mathrm{mg} / \mathrm{dl}$, normomagnesemia 1.7$2.4 \mathrm{mg} / \mathrm{dl}$, and hypermagnesemia $>2.4 \mathrm{mg} / \mathrm{dl}$ ). We used the time-dependent Cox model to examine the nonlinear relationship between mortality and $\mathrm{Mg}$ levels as the continuous time-varying variable with restricted cubic splines (4 knots). In the spline model, the lower range of normal $\mathrm{Mg}$ levels $(1.7 \mathrm{mg} / \mathrm{dl})$ was set to the reference $(H R=1)$. Three models were used for confounder correction: Model 1 was unadjusted; Model 2 was adjusted for baseline demographic characteristics, including age, gender, admission type, ethnicity, marital status, and insurance; and Model 3 was further adjusted for mean arterial pressure (MAP), weight, $\mathrm{MgSO}_{4}$ supplement, ventilator(VENT), continuous renal replacement treatment (CRRT), use of vasopressor (VASO), AKI, hemoglobin, potassium, platelets, white blood cells(WBCs), chloride, lactate, sodium, creatinine, bicarbonate, heart rate, respiratory rate, temperature, saturation of peripheral oxygen $\left(\mathrm{SpO}_{2}\right)$, urea nitrogen $(\mathrm{BUN})$, and infection site.

Additionally, to examine the associations of 28- and 90-day mortality with $\mathrm{Mg}$ levels pre- and post- $\mathrm{MgSO}_{4}$ supplementation, we further performed a time-fixed and time-dependent Cox model as well as restricted cubic splines. Pre- $\mathrm{MgSO}_{4} \mathrm{Mg}$ levels were defined as the baseline $\mathrm{Mg}$ before $\mathrm{MgSO}_{4}$ supplementation and analyzed as the time-fixed variable. The subsequent $\mathrm{Mg}$ levels post- $\mathrm{MgSO}_{4}$ were treated as the timevarying variable.

\section{Results}

\section{Study cohort}

In total, 8175 patients were included in this study (Figure 1). Patients with hypo-, normo- and hypermagnesemia were $22.87 \%, 66.84 \%$, and $10.29 \%$, respectively. Patients were 67.51 years old on average, and $63.73 \%$ were male. The average SAPS-II and SOFA scores were 34.23 and 4.57 , respectively. A total of 8175 patients were included in our study, among them, $1870(22.87 \%), 5464(66.84 \%)$, and $841(10.29 \%)$ patients had hypo-, normo-, and hypermagnesemia, respectively (Table 1$)$. The mean baseline $\mathrm{Mg}$ level was $1.95 \mathrm{mmol} / \mathrm{L}$. Characteristics such as age, respiratory rate, heart rate, temperature, MAP, weight, lactate level, $\mathrm{SpO}_{2}$, WBC, platelets, creatinine, hemoglobin, calcium, potassium, BUN, 
bicarbonate, daily urine output, baseline Mg level and SAPS-II, SOFA, Charlson comorbidity index (CCI) and GCS scores, infection site, VENT, VASO, CRRT, and incidence of AKI were found to be significantly different between survivors and nonsurvivors (Table 1).

\section{Association of Mg levels with 28- and 90-day mortality}

Compared to normomagnesemia, there was a significant association of hypermagnesemia with 28- and 90-day mortality $(\mathrm{HR}=1.68,95 \% \mathrm{Cl}=1.47-1.91 ; \mathrm{HR}=1.64,95 \% \mathrm{Cl}=1.44-1.87)$ but hypomagnesemia showed no statistical significance $(p>0.916)$ when compared with normomagnesemia in the unadjusted model (Table 2). In full correction (Table 2 Model 3), the hazard ratio (HR) of hypermagnesemia decreased to $1.42(95 \% \mathrm{Cl}=1.23-1.64)$ and $1.42(95 \% \mathrm{Cl}=1.24-1.64)$ at 28 and 90 days, respectively. The results of the spline model (Figure 2) based on the continuous variable were consistent with the results of the categorical variable (Table 2). Higher Mg levels were associated with an increased risk of 28-and 90-day mortality in all correction models. However, there was no significant association between lower Mg levels and mortality (Figure 2).

For further confirmation of our results, we developed sensitivity analyses from different points and obtained similar results (Supplement Table).

\section{The association between mortality and $\mathrm{Mg}$ levels pre- and post- $\mathrm{MgSO}_{4}$ supplementation}

$\mathrm{Mg}$ levels of the pre- $\mathrm{MgSO}_{4}$ supplement were not associated with mortality at 28- and 90 days after adjustment for confounders (Table 3). However, in patients receiving $\mathrm{MgSO}_{4}$ supplement, an increased risk of 28-day mortality was found in hypermagnesemia compared to normomagnesemia (HR=1.69, 95\% $\mathrm{Cl}=1.40-2.03$ ). When further adjusted for the baseline characteristics (Table 3 Model 3), subsequent hypermagnesemia $(\mathrm{HR}=1.44,95 \% \mathrm{Cl}=1.17-1.78, p=0.001)$ and even still hypomagnesemia $(\mathrm{HR}=1.51,95 \%$ $\mathrm{Cl}=1.15-1.99, p=0.003)$ after $\mathrm{MgSO}_{4}$ supplementation were significantly associated with increased 28-day mortality after adjustment for confounders. The association among 90-day mortality showed similar results.

In the spline model regarding pre- $\mathrm{MgSO}_{4}$ supplementation, there was no significant association between mortality and Mg levels (Figure $3 \mathrm{~A}$ and $\mathrm{D}$ ). The mortality in hypermagnesemia seemed higher than that in patients in the normal range, but the difference was not statistically significant. After correction, the reference line was included in the $95 \% \mathrm{Cl}$ of $\mathrm{HRs}$ for any $\mathrm{Mg}$ concentrations, which indicated no significant association between baseline $\mathrm{Mg}$ and 28- and 90-day mortality (Figure 3 B-C E-F). However, there was a sharp U-shaped relationship between $\mathrm{Mg}$ levels and 28- and 90-day mortality post-MgSO ${ }_{4}$ supplementation (Figure 4). Unlike the results in the total population (Table 2), after receiving $\mathrm{MgSO}_{4}$ supplementation, patients with subsequently higher and lower $\mathrm{Mg}$ levels had a steeply increased risk of 28- and 90-day mortality, and this association remained after adjusting for confounders. More importantly, the risk of mortality caused by subsequent lower $\mathrm{Mg}$ after $\mathrm{MgSO}_{4}$ seemed deadier than those in higher $\mathrm{Mg}$ after correction (Model 3 in Table 3 and Figure $4 \mathrm{C}$ and $\mathrm{F}$ ). 


\section{Discussion}

In this retrospective study, a total of 8175 patients were analyzed, and the proportions of patients with hypo-, normo-, and hypermagnesemia were $22.87 \%, 66.84 \%$, and $10.29 \%$, respectively. Of note, hypermagnesemia was significantly associated with both 28-day and 90-day mortality of septic patients when adjusted for cofounders. Unexpectedly, septic patients with subsequent hyper- and even still hypomagnesemia who received $\mathrm{MgSO}_{4}$ supplementation were found to have a significantly increased risk of 28-day and 90-day mortality.

$\mathrm{Mg}$, the so-called "the forgotten electrolyte", is an essential element of life support[17, 18]. Magnesium disorders are commonly reported in critically ill patients and a great number of patients are characterized by hypomagnesemia, with a range of $22 \%$ and $60 \%[3]$. Our study confirmed that the morbidity of hypomagnesemia is as high as $22.87 \%$, which was consistent with a previous report[19]. Interestingly, the incidence of hypermagnesemia was almost one-half that of hypomagnesemia in septic patients. Perhaps due to the low incidence of hypermagnesemia in the past, we ignored this type of electrolyte disorder. There is no magnesium regulatory system other than urinary excretion, and Mg levels rise as kidney function declines[20]. Unfortunately, more than $50 \%$ of the causes of acute kidney injury (AKI) are sepsis [21], and AKI may result in hypermagnesemia in septic patients. Due to the development and popularity of CRRT, hypermagnesemia was less frequent than hypomagnesemia.

Notably, both hypomagnesemia and hypermagnesemia are associated with disease severity and various clinical symptoms, including cardiac arrhythmias, neurotoxicity, diminished deep tendon reflexes, muscle weakness and even cardiac arrest[3]. Several studies revealed that hypomagnesemia was associated with increased mortality and poor prognosis in critically ill patients with a higher prevalence of severe sepsis and septic shock[11, 15]. For example, a prospective observational study showed that patients who developed hypomagnesemia had significantly longer ICU stays and higher mortality[11]. Limaye et al[15] demonstrated that patients with hypomagnesemia needed longer mechanical ventilation support and had higher mortality than those with normal Mg levels. Similarly, two studies[22, 23] on a relatively large number of patients also concluded that hypomagnesemia was associated with higher mortality. Studies have shown that hypomagnesemia increases the mortality of patients, and a small number of studies have also found that hypermagnesemia can increase the mortality of patients. In a crosssectional study by Haider et al[24], the authors analyzed baseline Mg concentrations of over 5000 patients and showed that hypermagnesemia was a strong independent risk factor for mortality in a multivariate Cox regression model. Our study evaluated the time-weighted $\mathrm{Mg}$ value because this would reflect the total $\mathrm{Mg}$ exposure during their ICU stay, which we believe would be more representative to reveal the association between $\mathrm{Mg}$ and mortality. Unexpectedly, hypermagnesemia was significantly associated with increased 28-day and 90-day mortality. In addition, to explore the nonlinear relationship between $\mathrm{Mg}$ and our primary endpoints, we used restricted cubic splines based on a time-dependent model, and the results of the spline model were the same as those of the Cox model. For further confirmation of our results, we developed sensitivity analyses from different views and obtained similar results. 
Therefore, combined with our study, hypomagnesemia was not associated with mortality while hypermagnesemia was harmful to septic patients. The reasons may be as follows. At the acute phase of sepsis, the acquired causes of hypomagnesemia can be attributed to decreased oral intake or gastrointestinal absorption, or redistribution triggered by severe illness, or liquid dilution during fluid resuscitation[25, 26]. We may speculate that low levels of serum Mg could be relatively transient and be adjusted or even reversed with the onset of AKI or subsequent supplementation with magnesium sulfate. Previous studies $[3,11,27]$ mainly focused on baseline Mg concentrations at admission, which would not reflect the whole level of $\mathrm{Mg}$, thus ignoring some potential risk factors during the development of sepsis that could influence the mortality rate. Hypermagnesemia might cause severely lowered blood pressure, bradycardia, respiratory paralysis, coma, and cardiac arrest, which might aggressively deteriorate sepsis development[28]. The excretion of $\mathrm{Mg}$ is controlled primarily by the kidney[29], which is one of the most vulnerable organs during the development of sepsis[30]. Hypermagnesemia may be associated with acute kidney injury[31] and thus cause poor prognosis in septic patients. Since the impact of hypermagnesemia in septic patients has been studied less than hypomagnesemia, the specific mechanism of hypermagnesemia on body function remains unclear.

Since the treatment of hypomagnesemia remains unclear, we further explored the effects of $\mathrm{Mg}$ supplements (magnesium sulfate, $\mathrm{MgSO}_{4}$ ) on the relationship between serum $\mathrm{Mg}$ levels and mortality. Considering the different timings of $\mathrm{Mg}$ supplementation in different patients, we assessed Mg levels in a time-fixed and time-varying manner. A time-fixed manner regarded baseline $\mathrm{Mg}$ levels before receiving magnesium sulfate and a time-varying manner was presented as the $\mathrm{Mg}$ levels after magnesium sulfate supplementation. Interestingly, in our present study, $\mathrm{Mg}$ levels of the pre- $\mathrm{MgSO}_{4}$ supplement were not associated with mortality when adjusted for confounders, however, after the administration of the $\mathrm{MgSO}_{4}$ supplement, the subsequent hyper- and hypomagnesemia were associated with increased 28-day and 90day mortality. The further spline model showed similar results. This result indicated that supplementation with magnesium sulfate might be positively associated with the mortality of septic patients. Although there is an ongoing argument that mild hypermagnesemia may be beneficial to patients because of the anti-inflammatory, antioxidant, and anti-apoptotic effects of $\mathrm{Mg}[32,33]$, we still emphasize that clinical physicians should be cautious about Mg oversupplementation in septic patients. Since kidneys are vulnerable during sepsis[30], and patients with kidney function impairment are at risk for severe hypermagnesemia if large doses of $\mathrm{Mg}$ are given[20], supplementation could cause poor manifestations. In addition, we could not analyze the bolus speed and doses of $\mathrm{MgSO}_{4}$ supplementation or the timing of subsequent $\mathrm{Mg}$ concentration monitoring, and we can only speculate that the speed and doses may affect the relationship between $\mathrm{Mg}$ levels and mortality. Of note, serum $\mathrm{Mg}$ levels do not correlate well with total body stores, as the majority are intracellular, and serum concentrations may be transiently elevated for a few hours after administration of an IV dose[29]. Therefore, we suggest that Mg levels should be measured daily or more frequently and be controlled more strictly in septic patients receiving magnesium sulfate therapy. 
There are some limitations of this study. First, we could only evaluate serum Mg levels during the whole ICU stay due to the lack of total reported $\mathrm{Mg}$ and ionized Mg levels. Some studies revealed that ionized $\mathrm{Mg}$ might be a more physiologically relevant marker than total Mg levels[10, 34, 35]. Studies on total Mg and ionized $\mathrm{Mg}$ in septic patients should be performed to further disclose the relationship between $\mathrm{Mg}$ levels and mortality rates. Second, we did not take into consideration the association between $\mathrm{Mg}$ abnormalities and acute kidney injury. Third, we did not analyze the degree of hypo- or hypermagnesemia, or the relevant poor outcomes, since patients with different degrees of hypo- or hypermagnesemia may exhibit different symptoms and thus have various prognoses. Fourth, this study was observational and could not demonstrate the causal-relationship between $\mathrm{Mg}$ levels and outcome. Fifth, although we adjusted for potential confounding factors, there might also be residual confounding factors. Sixth, as we can see in spline analysis, the confidence intervals were wide at higher magnesium due to its sparse sample size. Thus, the results with extreme levels of potassium should be interpreted with caution.

\section{Conclusion}

Hypermagnesemia was significantly associated with higher risk of 28-day and 90-day mortality. After supplementation with magnesium sulfate, the subsequent hypomagnesemia and hypermagnesemia were associated with increased mortality, suggesting that we should be cautious about $\mathrm{Mg}$ oversupplementation and be more rigorous to monitor Mg levels.

\section{Declarations}

\section{Ethics approval and consent to participate}

The establishment of this database was approved by the Massachusetts Institute of Technology (Cambridge, MA) and Beth Israel Deaconess Medical Center (Boston, MA), and consent was obtained for the original data collection. Thus, the ethical approval statement and the need for informed consent were waived.

\section{Consent for publication}

Not applicable

\section{Availability of data and materials}

Data in the article can be obtained from MIMIC-IV database(0.4version) (https://mimic.physionet. org/)

\section{Competing interests}

The authors declare that they have no competing interests.

\section{Funding}


This work was supported by the Natural Science Foundation of Guangdong Province, China [grant number 2020A151501361], the Natural Science Foundation of China [grant numbers 81701955] and the Clinical Research Program of NanFang Hospital, Southern Medical University [grant number 2018CR047] and Wu Jieping Medical Foundation, China [grant number 320.6750.18431].

\section{Authors' contributions}

LL and QH conducted data extraction. SZ, HH and JW conducted statistical analysis. ZZ and SA designed the study and wrote the manuscript. ZC analyzed and interpreted the result. All authors read and approved the final manuscript.

\section{Acknowledgements}

Not applicable

\section{References}

1. Panahi Y, Mojtahedzadeh M, Najafi A, Ghaini MR, Abdollahi M, Sharifzadeh M, Ahmadi A, Rajaee SM, Sahebkar A. The role of magnesium sulfate in the intensive care unit. EXCLI J. 2017;16:464-82.

2. Hansen BA, Bruserud O. Hypomagnesemia in critically ill patients. J Intensive Care. 2018;6:21.

3. Velissaris D, Karamouzos V, Pierrakos C, Aretha D, Karanikolas M. Hypomagnesemia in Critically III Sepsis Patients. J Clin Med Res. 2015;7(12):911-8.

4. Noormandi A, Khalili $H$, Mohammadi M, Abdollahi A. Effect of magnesium supplementation on lactate clearance in critically ill patients with severe sepsis: a randomized clinical trial. Eur $\mathrm{J}$ Clin Pharmacol. 2020;76(2):175-84.

5. Kraft MD, Btaiche IF, Sacks GS, Kudsk KA. Treatment of electrolyte disorders in adult patients in the intensive care unit. Am J Health Syst Pharm. 2005;62(16):1663-82.

6. Van Laecke S. Hypomagnesemia and hypermagnesemia. Acta Clin Belg. 2019;74(1):41-7.

7. Laupland KB, Tabah A, Jacobs N, Ramanan M. Determinants of serum magnesium abnormalities and outcome among admissions to the intensive care unit. Anaesthesia Critical Care Pain Medicine. 2020;39(6):793-7.

8. Tong GM, Rude RK. Magnesium deficiency in critical illness. J Intensive Care Med. 2005;20(1):3-17.

9. Guerin C, Cousin C, Mignot F, Manchon M, Fournier G. Serum and erythrocyte magnesium in critically ill patients. Intensive Care Med. 1996;22(8):724-7.

10. Escuela MP, Guerra M, Anon JM, Martinez-Vizcaino V, Zapatero MD, Garcia-Jalon A, Celaya S. Total and ionized serum magnesium in critically ill patients. Intensive Care Med. 2005;31(1):151-6.

11. Soliman HM, Mercan D, Lobo SS, Melot C, Vincent JL. Development of ionized hypomagnesemia is associated with higher mortality rates. Crit Care Med. 2003;31(4):1082-7.

12. Rubeiz GJ, Thill-Baharozian M, Hardie D, Carlson RW. Association of hypomagnesemia and mortality in acutely ill medical patients. Crit Care Med. 1993;21(2):203-9. 
13. Dellinger RP, Levy MM, Rhodes A, Annane D, Gerlach H, Opal SM, Sevransky JE, Sprung CL, Douglas IS, Jaeschke R, et al. Surviving Sepsis Campaign: International Guidelines for Management of Severe Sepsis and Septic Shock, 2012. Intensive Care Med. 2013;39(2):165-228.

14. Singer M, Deutschman CS, Seymour CW, Shankar-Hari M, Annane D, Bauer M, Bellomo R, Bernard GR, Chiche J-D, Coopersmith CM, et al: The Third International Consensus Definitions for Sepsis and Septic Shock (Sepsis-3). Jama 2016, 315(8):801.

15. Limaye CS, Londhey VA, Nadkart MY, Borges NE. Hypomagnesemia in critically ill medical patients. J Assoc Physicians India. 2011;59:19-22.

16. Upala S, Jaruvongvanich V, Wijarnpreecha K, Sanguankeo A. Hypomagnesemia and mortality in patients admitted to intensive care unit: a systematic review and meta-analysis. QJM. 2016;109(7):453-9.

17. Vormann J. Magnesium and Kidney Health - More on the 'Forgotten Electrolyte'. Am J Nephrol. 2016;44(5):379-80.

18. Ahmed F, Mohammed A. Magnesium: The Forgotten Electrolyte-A Review on Hypomagnesemia. Med Sci (Basel) 2019, 7(4).

19. Moskowitz A, Lee J, Donnino MW, Mark R, Celi LA, Danziger J. The Association Between Admission Magnesium Concentrations and Lactic Acidosis in Critical Illness. J Intensive Care Med. 2016;31(3):187-92.

20. Felsenfeld AJ, Levine BS, Rodriguez M. Pathophysiology of Calcium, Phosphorus, and Magnesium Dysregulation in Chronic Kidney Disease. Semin Dial. 2015;28(6):564-77.

21. Ma S, Evans RG, Iguchi N, Tare M, Parkington HC, Bellomo R, May CN, Lankadeva YR. Sepsis-induced acute kidney injury: A disease of the microcirculation. Microcirculation. 2019;26(2):e12483.

22. Kumar S, Honmode A, Jain S, Bhagat V. Does magnesium matter in patients of Medical Intensive Care Unit: A study in rural Central India. Indian J Crit Care Med. 2015;19(7):379-83.

23. Chen $M$, Sun $R$, Hu B. [The influence of serum magnesium level on the prognosis of critically ill patients]. Zhonghua wei zhong bing ji jiu yi xue. 2015;27(3):213-7.

24. Haider DG, Lindner G, Ahmad SS, Sauter T, Wolzt M, Leichtle AB, Fiedler GM, Exadaktylos AK, Fuhrmann V. Hypermagnesemia is a strong independent risk factor for mortality in critically ill patients: results from a cross-sectional study. Eur J Intern Med. 2015;26(7):504-7.

25. Al Alawi AM, Majoni SW, Falhammar H. Magnesium and Human Health: Perspectives and Research Directions. International Journal of Endocrinology. 2018;2018:1-17.

26. Lee JW. Fluid and Electrolyte Disturbances in Critically III Patients. Electrolytes Blood Pressure. 2010;8(2):72.

27. Jiang P, Lv Q, Lai T, Xu F. Does Hypomagnesemia Impact on the Outcome of Patients Admitted to the Intensive Care Unit? A Systematic Review and Meta-Analysis. Shock. 2017;47(3):288-95.

28. of loMU. Intakes DR. Dietary Reference Intakes for Calcium, Phosphorus, Magnesium, Vitamin D, and Fluoride. Washington (DC): National Academies Press (US); 1997. 
29. Jahnen-Dechent W, Ketteler M. Magnesium basics. Clin Kidney J. 2012;5(Suppl 1):i3-14.

30. Bellomo R, Kellum JA, Ronco C, Wald R, Martensson J, Maiden M, Bagshaw SM, Glassford NJ, Lankadeva Y, Vaara ST, et al. Acute kidney injury in sepsis. Intensive Care Med. 2017;43(6):816-28.

31. Meurer M, Hocherl K. Deregulated renal magnesium transport during lipopolysaccharide-induced acute kidney injury in mice. Pflugers Arch. 2019;471(4):619-31.

32. de Baaij JH, Hoenderop JG, Bindels RJ. Magnesium in man: implications for health and disease. Physiol Rev. 2015;95(1):1-46.

33. Van Laecke S, Van Biesen W, Vanholder R. Hypomagnesaemia, the kidney and the vessels. Nephrol Dial Transplant. 2012;27(11):4003-10.

34. Rooney MR, Rudser KD, Alonso A, Harnack L, Saenger AK, Lutsey PL. Circulating lonized Magnesium: Comparisons with Circulating Total Magnesium and the Response to Magnesium Supplementation in a Randomized Controlled Trial. Nutrients 2020, 12(1).

35. Glasdam SM, Glasdam S, Peters GH. The Importance of Magnesium in the Human Body: A Systematic Literature Review. Adv Clin Chem. 2016;73:169-93.

\section{Tables}

Table 1 Baseline Characteristics of patients in the study 


\begin{tabular}{|c|c|c|c|c|}
\hline var & Total $(n=8175)$ & Survival $(\mathrm{n}=6790)$ & Death $(n=1385)$ & $\mathrm{P}$ \\
\hline Age, yr & $\begin{array}{l}\text { 68.94(57.08- } \\
80.41)\end{array}$ & $\begin{array}{l}68.17(56.30- \\
79.85)\end{array}$ & $\begin{array}{l}72.47(61.36- \\
82.70)\end{array}$ & $<0.001$ \\
\hline Male, $\%$ & $5210(63.73)$ & $4331(63.78)$ & $879(63.47)$ & 0.822 \\
\hline $\begin{array}{l}\text { Admission type, } \\
\text { emergency, \% }\end{array}$ & $4122(50.42)$ & $3419(50.35)$ & 703(50.76) & 0.784 \\
\hline Non-white, \% & $2780(34.01)$ & $2265(33.36)$ & $515(37.18)$ & 0.006 \\
\hline Married, \% & $3283(40.16)$ & $2724(40.12)$ & $559(40.36)$ & 0.866 \\
\hline Medicare, \% & 4692(57.39) & $3856(56.79)$ & $836(60.36)$ & 0.014 \\
\hline Respiratory rate (/min) & $\begin{array}{l}\text { 19.81(17.27- } \\
22.77)\end{array}$ & $\begin{array}{l}19.45(17.09- \\
22.31)\end{array}$ & $\begin{array}{l}21.57(18.61- \\
24.84)\end{array}$ & $<0.001$ \\
\hline Heart rate (bpm) & $\begin{array}{l}87.54(76.53- \\
100.08)\end{array}$ & $\begin{array}{l}\text { 86.74(75.96- } \\
98.88)\end{array}$ & $\begin{array}{l}\text { 92.48(80.15- } \\
106.58)\end{array}$ & $<0.001$ \\
\hline Temperature $\left({ }^{\circ} \mathrm{C}\right)$ & $\begin{array}{l}36.86(36.59- \\
37.22)\end{array}$ & $\begin{array}{l}36.88(36.62- \\
37.23)\end{array}$ & $36.77(36.4-37.18)$ & $<0.001$ \\
\hline $\mathrm{MAP} \otimes \mathrm{mmHg} \rrbracket$ & $\begin{array}{l}77.36(71.87- \\
84.94)\end{array}$ & $\begin{array}{l}\text { 78.05(72.57- } \\
85.64)\end{array}$ & $\begin{array}{l}73.99(68.33- \\
80.89)\end{array}$ & $<0.001$ \\
\hline Weight $\triangle \mathrm{kg} \rrbracket$ & 77.15(64.4-94) & 77.4(64.99-94.64) & $75.8(62.6-92)$ & $<0.001$ \\
\hline Lactate $(\mathrm{mmol} / \mathrm{L})$ & $1.9(1.3-2.9)$ & $1.73(1.25-2.5)$ & $2.8(1.75-4.99)$ & $<0.001$ \\
\hline SpO2 (\%) & $\begin{array}{l}\text { 96.93(95.54- } \\
98.28)\end{array}$ & $\begin{array}{l}97.00(95.69- \\
98.30)\end{array}$ & $\begin{array}{l}96.44(94.52- \\
98.19)\end{array}$ & $<0.001$ \\
\hline WBC $\left(\times 10^{9}\right)$ & 11.95(8.33-16.7) & $11.7(8.3-16.25)$ & $13.4(8.58-19.49)$ & $<0.001$ \\
\hline Platelets $\left(\times 10^{9}\right)$ & $\begin{array}{l}\text { 195.75(134- } \\
272.5)\end{array}$ & $200(141-275.19)$ & $170(96.67-258)$ & $<0.001$ \\
\hline Creatinine (mg/dL) & $1.12(0.8-1.83)$ & $1.05(0.75-1.68)$ & $1.6(1-2.55)$ & $<0.001$ \\
\hline Hemoglobin $(\mathrm{mg} / \mathrm{dL})$ & $10.2(8.93-11.7)$ & $10.3(9-11.75)$ & $9.8(8.5-11.39)$ & $<0.001$ \\
\hline Chloride (mmol/L) & $\begin{array}{l}103.67(99.67- \\
107.5)\end{array}$ & $\begin{array}{l}103.75(100- \\
107.5)\end{array}$ & 103.33(98.6-108) & 0.140 \\
\hline Calcium (mg/dl) & $8.2(7.7-8.7)$ & $8.2(7.7-8.7)$ & $8.08(7.55-8.6)$ & $<0.001$ \\
\hline Potassium (mmol/L), & $4.13(3.78-4.55)$ & $4.1(3.77-4.5)$ & $4.28(3.86-4.83)$ & $<0.001$ \\
\hline Sodium (mmol/L), & $138(135-141)$ & $\begin{array}{l}\text { 138(135.33- } \\
140.89)\end{array}$ & $\begin{array}{l}138(134.5- \\
141.67)\end{array}$ & 0.409 \\
\hline BUN (mg/dl), & $24.33(15-40.67)$ & $22.5(14.5-37.25)$ & $34.86(22-54.2)$ & $<0.001$ \\
\hline Bicarbonate (mmol/L) & $\begin{array}{l}22.33(19.33- \\
25.25)\end{array}$ & $22.67(20-25.5)$ & $20.25(16.5-24)$ & $<0.001$ \\
\hline
\end{tabular}




\begin{tabular}{|c|c|c|c|c|}
\hline Daily urine output, (L/d) & $1.38(0.81-2.2)$ & $1.5(0.93-2.32)$ & $0.77(0.28-1.43)$ & $<0.001$ \\
\hline SAPS-II & $33(25-42)$ & $31(24-39)$ & $44(35-54)$ & $<0.001$ \\
\hline SOFA & $4(3-6)$ & $4(2-6)$ & $6(4-8)$ & $<0.001$ \\
\hline $\mathrm{CCl}$ & $6(4-8)$ & $5(4-8)$ & $7(5-9)$ & $<0.001$ \\
\hline GCS & $14(10-15)$ & $14(11-15)$ & $10(5-14)$ & $<0.001$ \\
\hline \multicolumn{5}{|l|}{ Baseline magnesemia } \\
\hline Magnesemia, mg/dL & $1.9(1.7-2.2)$ & $1.9(1.7-2.1)$ & $2.0(1.7-2.3)$ & $<0.001$ \\
\hline Hypermagnesemia, \% & $841(10.29)$ & $641(9.44)$ & $200(14.44)$ & $<0.001$ \\
\hline Hypomagnesemia, \% & 1870(22.87) & $1609(23.70)$ & 261(18.84) & \\
\hline Normomagnesemia, \% & $5464(66.84)$ & $4540(66.86)$ & $924(66.71)$ & \\
\hline VENT, n (\%) & 3941(48.21) & 2924(43.06) & 1017(73.43) & $<0.001$ \\
\hline CRRT, n (\%) & $384(4.70)$ & $180(2.65)$ & 204(14.73) & $<0.001$ \\
\hline VASO, n (\%) & $3575(43.73)$ & 2587(38.10) & 988(71.34) & $<0.001$ \\
\hline AKI, n (\%) & 5795(70.89) & $4537(66.82)$ & 1258(90.83) & $<0.001$ \\
\hline Magnesium Sulfate, n (\%) & $5113(62.54)$ & $4248(62.56)$ & $865(62.45)$ & 0.940 \\
\hline \multicolumn{5}{|l|}{ Infection site, \% } \\
\hline Blood & 2593(31.72) & 2070(30.49) & $523(37.76)$ & $<0.001$ \\
\hline Lung & $432(5.28)$ & $312(4.59)$ & $120(8.66)$ & $<0.001$ \\
\hline Stool & 131(1.60) & $96(1.41)$ & $35(2.53)$ & 0.003 \\
\hline Urine & 3203(39.18) & 2648(39.00) & $555(40.07)$ & 0.456 \\
\hline Other & 2661(32.55) & 2281(33.59) & $380(27.44)$ & $<0.001$ \\
\hline
\end{tabular}

Continuous variables are reported as median (interquartile range [IQR]).

MAP: mean arterial pressure, WBC: white blood cells, BUN: Urea Nitrogen, CCl: Charlson comorbidity index, VENT: ventilation, CRRT: continuous renal replacement therapy, VASO: vasopressor, AKI: acute kidney injury.

Table 2 Association of mortality and magnesium levels with time-dependent Cox model. 


\begin{tabular}{|c|c|c|c|c|c|}
\hline \multirow[b]{2}{*}{ Model } & \multirow[b]{2}{*}{ Magnesium status } & \multicolumn{2}{|l|}{ 28-day mortality } & \multicolumn{2}{|l|}{ 90-day mortality } \\
\hline & & $\mathrm{HR}(95 \% \mathrm{Cl})$ & $P$ & $\mathrm{HR}(95 \% \mathrm{Cl})$ & $P$ \\
\hline \multirow[t]{3}{*}{ Model 1} & Normal & 1.00 & & 1.00 & \\
\hline & Нyро- & $1.01(0.81-1.25)$ & 0.951 & $1.01(0.82-1.25)$ & 0.916 \\
\hline & Hyper- & $1.68(1.47-1.91)$ & $<0.001$ & $1.64(1.44-1.87)$ & $<0.001$ \\
\hline \multirow[t]{3}{*}{ Model 2} & Normal & 1.00 & & 1.00 & \\
\hline & Нypo- & $1.05(0.84-1.31)$ & 0.666 & $1.05(0.84-1.29)$ & 0.685 \\
\hline & Hyper- & $1.67(1.47-1.91)$ & $<0.001$ & $1.63(1.43-1.86)$ & $<0.001$ \\
\hline \multirow[t]{3}{*}{ Model 3} & Normal & 1.00 & & 1.00 & \\
\hline & Нypo- & $1.09(0.86-1.37)$ & 0.486 & $1.06(0.85-1.34)$ & 0.573 \\
\hline & Hyper- & $1.42(1.23-1.64)$ & $<0.001$ & $1.42(1.24-1.64)$ & $<0.001$ \\
\hline
\end{tabular}

Model 1: unadjusted

Model 2: adjusted age, gender, admission type, ethnicity, marital status, insurance

Model 3: further adjusted for MAP, weight, $\mathrm{MgSO}_{4}$ supplement, VENT, CRRT, VASO, AKI, daily urine output, hemoglobin, potassium, platelets, WBC, chloride, lactate, sodium, creatinine, bicarbonate, heartrate, resp rate, temperature, SpO2, BUN, infection site.

Table 3 The association of magnesium and 28-day mortality pre- and post- magnesium sulfate supplement. 


\begin{tabular}{|c|c|c|c|c|c|}
\hline \multirow[b]{2}{*}{ Correction } & \multirow[b]{2}{*}{ Status } & \multicolumn{2}{|c|}{ Pre-MgSO ${ }_{4}$ supplement } & \multicolumn{2}{|c|}{ Post-MgSO ${ }_{4}$ supplement } \\
\hline & & $\mathrm{HR}(95 \% \mathrm{Cl})$ & $\mathrm{P}$ & $\mathrm{HR}(95 \% \mathrm{Cl})$ & $\mathrm{P}$ \\
\hline \multicolumn{6}{|c|}{ 28-day mortality } \\
\hline \multirow[t]{3}{*}{ Model 1} & Normal & 1.00 & & 1.00 & \\
\hline & Нypo- & $1.08(0.93-1.26)$ & 0.325 & $1.22(0.94-1.59)$ & 0.128 \\
\hline & Hyper- & $1.28(1.02-1.60)$ & 0.036 & $1.69(1.40-2.03)$ & $<0.001$ \\
\hline \multirow[t]{3}{*}{ Model 2} & Normal & 1.00 & & 1.00 & \\
\hline & Нypo- & $1.07(0.92-1.25)$ & 0.362 & $1.34(1.03-1.73)$ & 0.028 \\
\hline & Hyper- & $1.27(1.01-1.60)$ & 0.045 & $1.68(1.39-2.02)$ & $<0.001$ \\
\hline \multirow[t]{3}{*}{ Model 3} & Normal & 1.00 & & 1.00 & \\
\hline & Hypo- & $0.98(0.83-1.15)$ & 0.795 & $1.51(1.15-1.99)$ & 0.003 \\
\hline & Hyper- & $1.00(0.76-1.31)$ & 0.984 & $1.44(1.17-1.78)$ & 0.001 \\
\hline \multicolumn{6}{|c|}{ 90-day mortality } \\
\hline \multirow[t]{3}{*}{ Model 1} & Normal & 1.00 & & 1.00 & \\
\hline & Нypo- & $1.09(0.93-1.26)$ & 0.287 & $1.23(0.96-1.58)$ & 0.108 \\
\hline & Hyper- & $1.22(0.97-1.55)$ & 0.093 & $1.66(1.37-2.00)$ & $<0.001$ \\
\hline \multirow[t]{3}{*}{ Model 2} & Normal & 1.00 & & 1.00 & \\
\hline & Нypo- & $1.08(0.93-1.26)$ & 0.312 & $1.34(1.05-1.72)$ & 0.021 \\
\hline & Hyper- & $1.21(0.96-1.54)$ & 0.109 & $1.64(1.36-1.98)$ & $<0.001$ \\
\hline \multirow[t]{3}{*}{ Model 3} & Normal & 1.00 & & 1.00 & \\
\hline & Нyро- & $0.98(0.82-1.17)$ & 0.792 & $1.53(1.18-1.99)$ & 0.001 \\
\hline & Hyper- & $0.98(0.75-1.28)$ & 0.881 & $1.43(1.16-1.77)$ & 0.001 \\
\hline
\end{tabular}

Model 1: unadjusted

Model 2: adjusted age, gender, admission type, ethnicity, marital status, insurance

Model 3: further adjusted for MAP, weight, $\mathrm{MgSO}_{4}$ supplement, VENT, CRRT, VASO, AKI, daily urine output, hemoglobin, potassium, platelets, WBC, chloride, lactate, sodium, creatinine, bicarbonate, heartrate, resp rate, temperature, $\mathrm{SpO} 2, \mathrm{BUN}$, infection site.

\section{Figures}




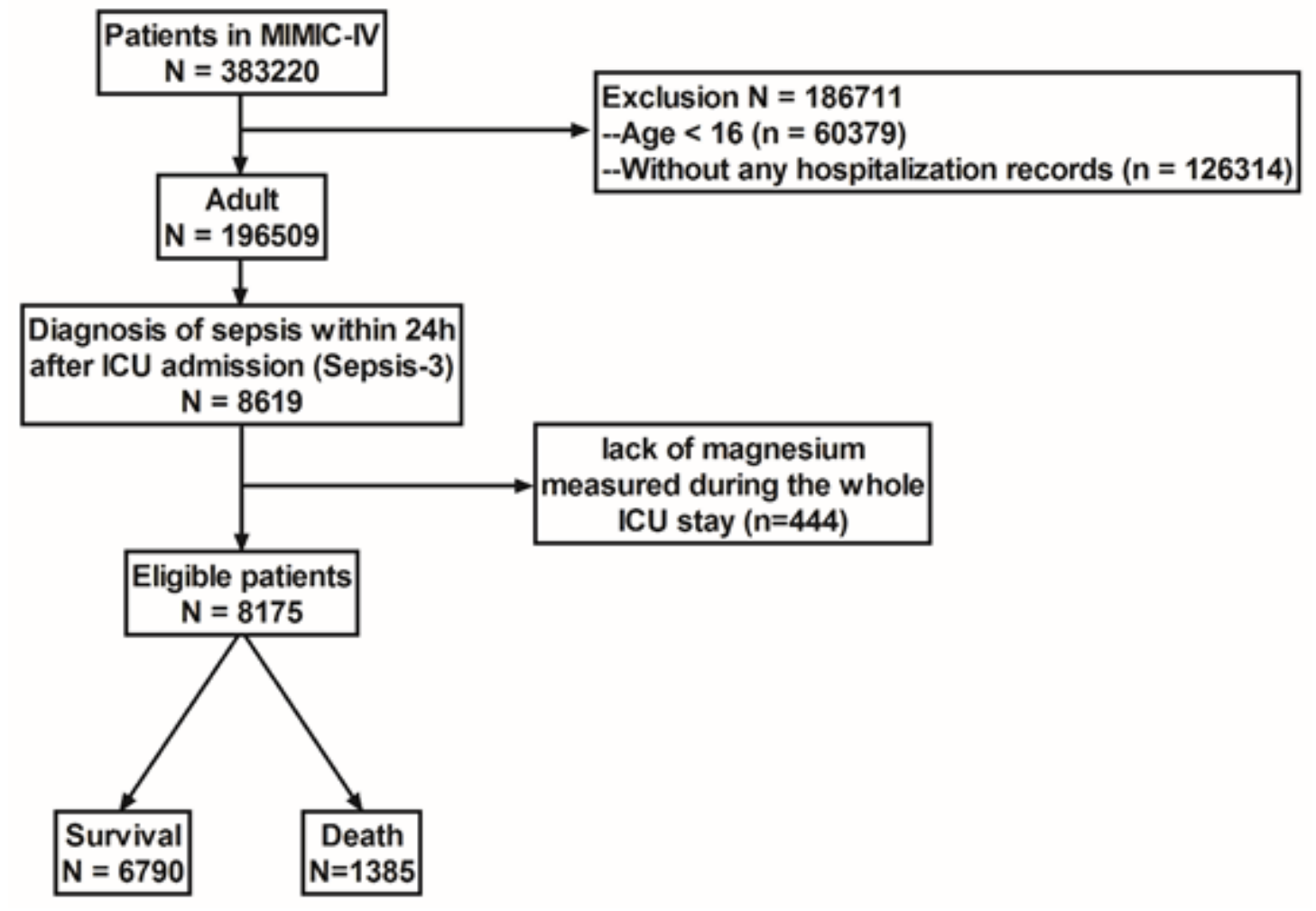

Figure 1

Flowchart of patients in the study.
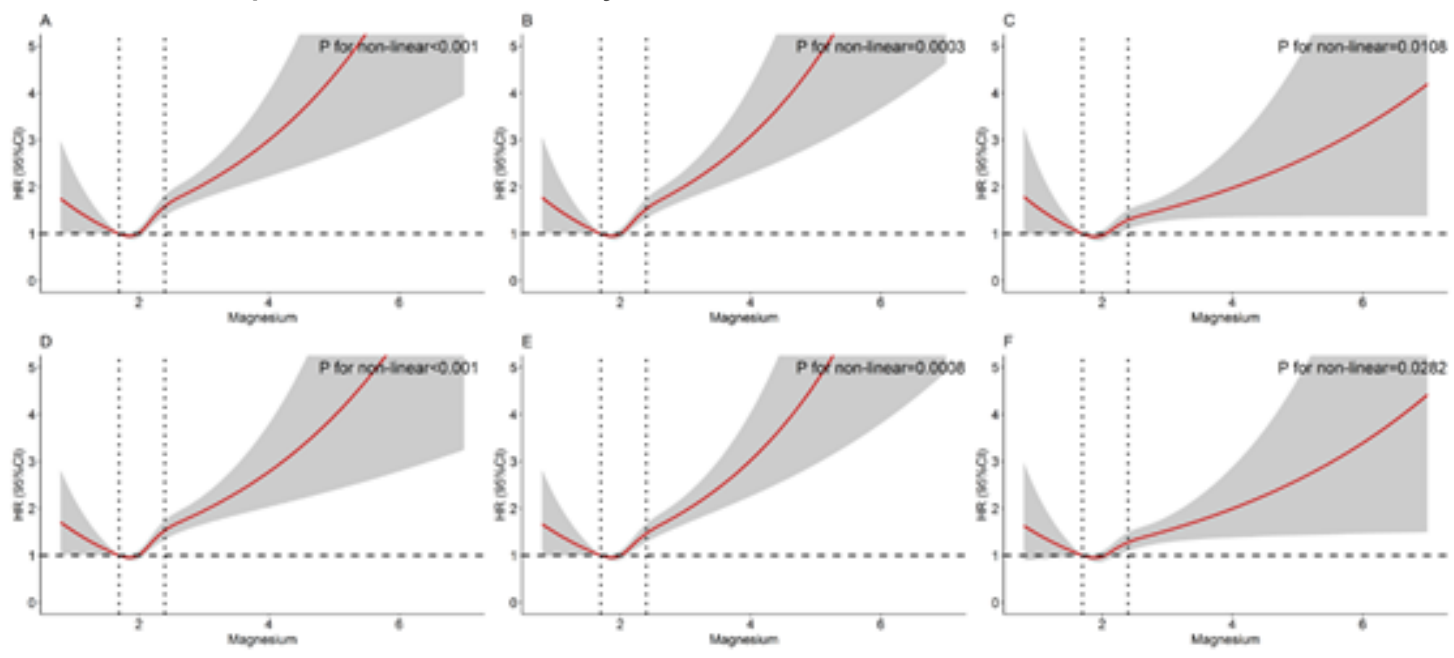

Figure 2

Association of mortality and continuous magnesium levels with restricted cubic splines in timedependent Cox model. Model 1: unadjusted Model 2: adjusted age, gender, admission type, ethnicity, marital status, insurance Model 3: further adjusted for MAP, weight, MgSO4 supplement, VENT, CRRT, VASO, AKI, daily urine output, hemoglobin, potassium, platelets, WBC, chloride, lactate, sodium, creatinine, bicarbonate, heartrate, resp rate, temperature, $\mathrm{SpO} 2, \mathrm{BUN}$, infection site. Dotted line denoted the normal range of magnesium in populations $(1.7-2.4 \mathrm{mg} / \mathrm{dl})$. 

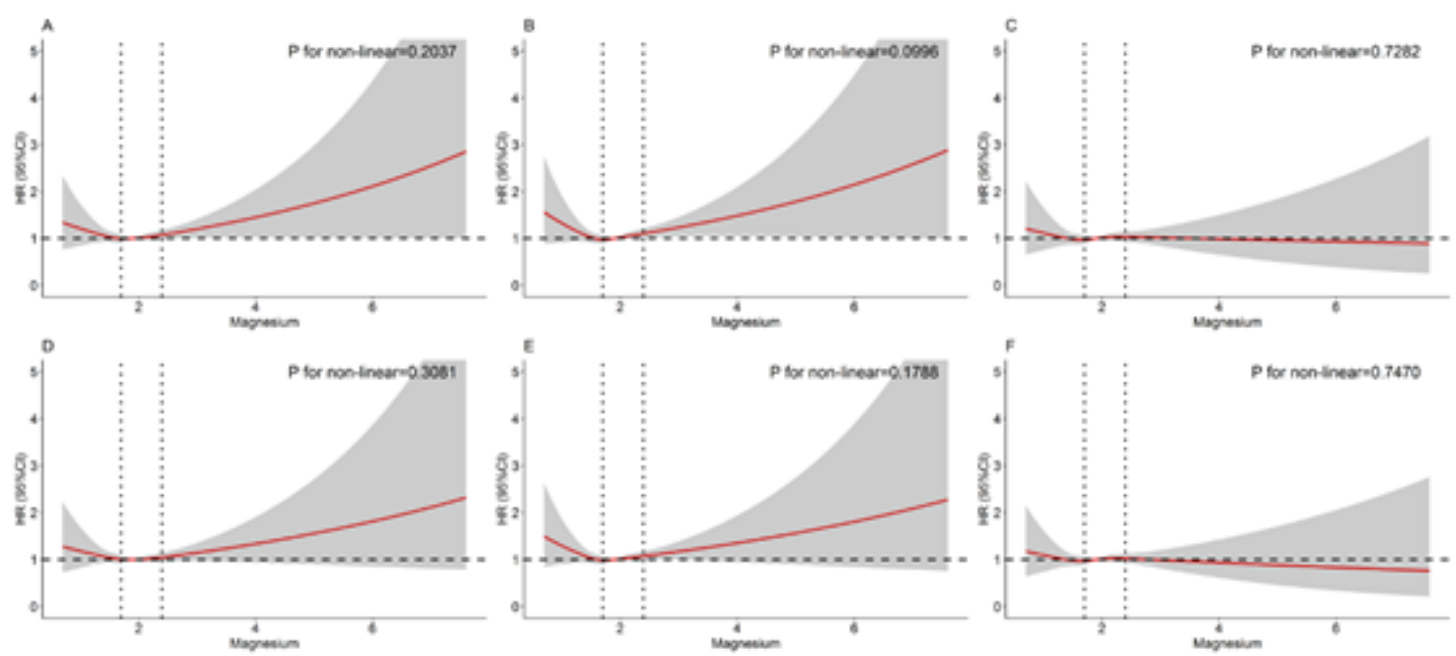

Figure 3

the association between mortality and magnesium levels pre-MgSO4 supplement. Model 1: unadjusted Model 2: further adjusted age, gender, admission type, ethnicity, marital status, insurance Model 3: further adjusted for MAP, weight, MgSO4 supplement, VENT, CRRT, VASO, AKI, daily urine output, hemoglobin, potassium, platelets, WBC, chloride, lactate, sodium, creatinine, bicarbonate, heartrate, resp rate, temperature, SpO2, BUN, infection site. Dotted line denoted the normal range of magnesium in populations $(1.7-2.4 \mathrm{mg} / \mathrm{dl})$.
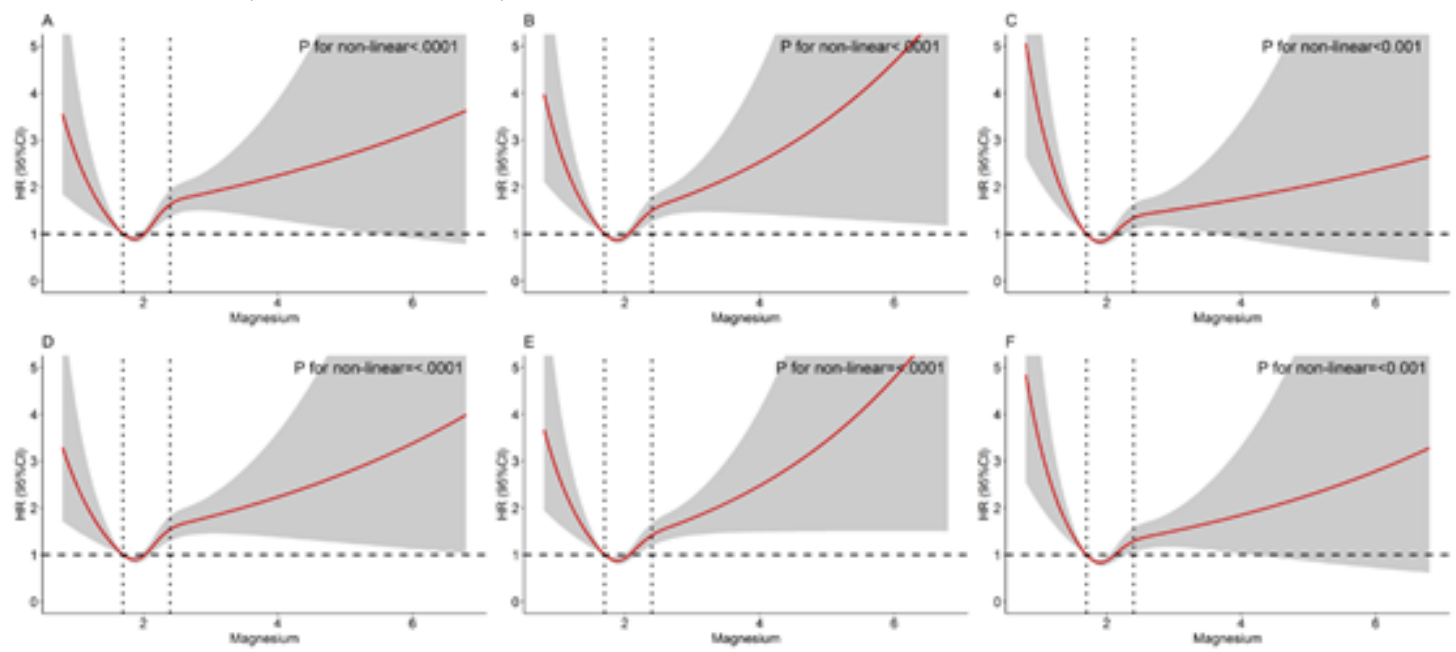

Figure 4

the association between mortality and magnesium post-MgSO4 supplement. Model 1: unadjusted Model 2: adjusted age, gender, admission type, ethnicity, marital status, insurance Model 3: further adjusted for MAP, weight, MgSO4 supplement, VENT, CRRT, VASO, AKI, daily urine output, hemoglobin, potassium, platelets, WBC, chloride, lactate, sodium, creatinine, bicarbonate, heartrate, resp rate, temperature, SpO2, BUN, infection site. Dotted line denoted the normal range of magnesium in populations $(1.7-2.4 \mathrm{mg} / \mathrm{dl})$. 